Historic, Archive Document

Do not assume content reflects current scientific knowledge, policies, or practices. 


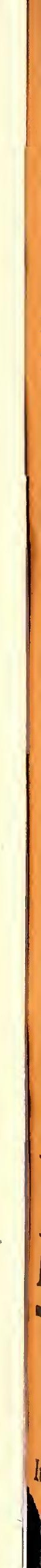




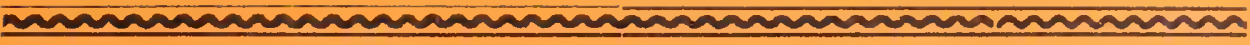

\section{SEED CORN}

On today's market card we have listed an assortment of the early, medium early and later varieties of Seed Corn showing germination $90 \%$ or better.

Indications are that there will be a good demand for Seed Corn of strong vitality. Would suggest anticipating your requirements so as to secure your supply while stocks are still available.

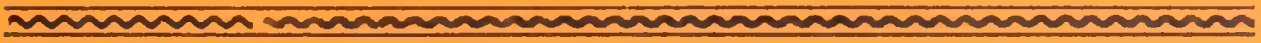

\section{Use This Post Card}

It is printed here tor your convenience

It gets prompt attention tout along dotted line

\section{Business Reply Card}

No Postage Stamp Necessary If Mailed In The United Statcs

2c.-POSTAGE WILL BE PAID BY-

THE ALBERT DICKINSON CO.

Lock Drawer 788
FIRST CLASS PERMIT NO. 1488

[Sec. 3841\%2 P. L. \& R.]

CHICAGO, ILL. 



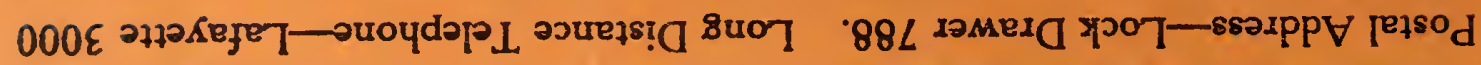

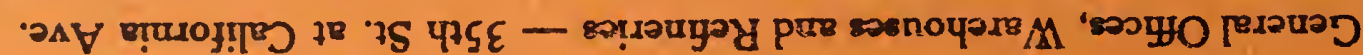

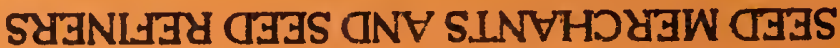

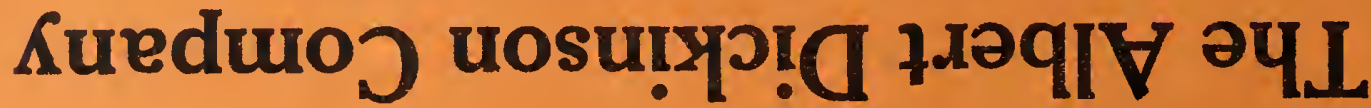

WOYJ SAORd S. $\forall \forall$ COLI

Marbet Qzotutivins from The Albert Dickinson Co. Seed Merchants and Seed Refiners CHICAGO, ILL., U. S. A.

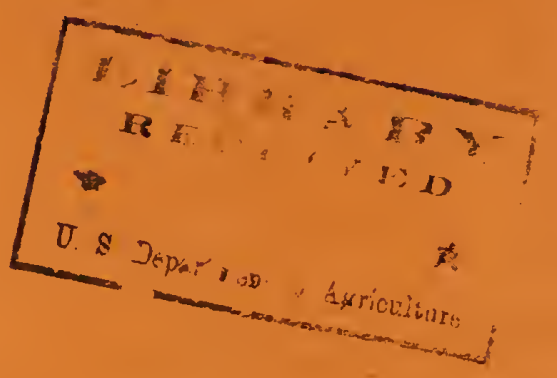

\section{First Class Mail}

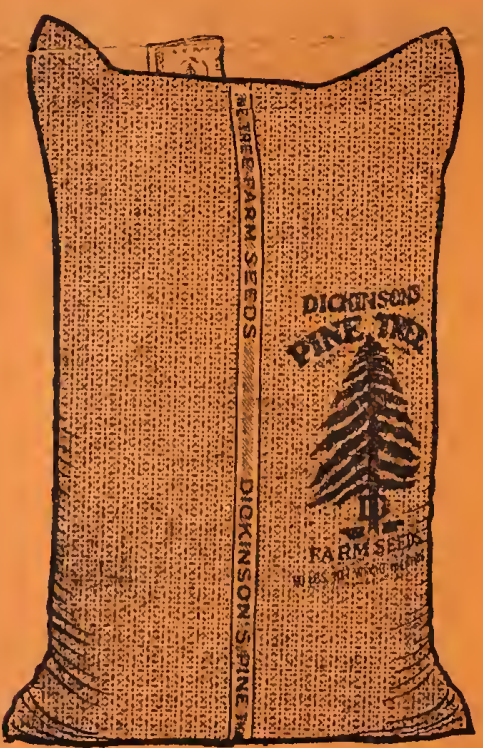

Order all or part of ycus regucioments this season packed in sealed

\section{PATENTED}

Eliminate all your losses and troubles with second-hand bags: pus a salesman to work for you in every farmer's home.

Towel Bag packing, bushel size, is now available for Timothy, all Clovers and Alfalfas. Each bag sealed. Easier to handle, easier to sell, more profitable. Weloomed in every household.

\section{SPLCLAL PRECRS \\ "Pine Tree" Seeds in Towel Bags}

CLOVERS \& ALFALFA @ 50c TIMOTHY @ 60c per $100 \mathrm{lbs}$. higher than prices quoted on other side-Beetres sizes Only Bage Iree-ziten Not Woldent When Packed Order "Pine Tree" and specify "in Towel Bags" 